\title{
Production of antibiotic of Microlides group from a local isolate of the bacterium Streptomyces rimosus
}

\author{
Mohammed B. Ismael Safaa I. Al-Obaiede* Khalid D. Ahmed \\ Department of biology / Education College for Pure Sciences \\ University of Mosul \\ Mohammed.ismael@gmail.com *drsafaaaloaede@yahoo.com khalid.ahmed@gmail.com
}

DOI: $\underline{10.33899 / \text { edusj.2019.162959 }}$

Received

$16 / 02 / 2014$
Accepted

08 / 05 / 2014

Key word: Streptomyces, rimosus, antibiotics, Macrolides

\begin{abstract}
Three local isolates of the genus Streptomyces were obtained from ten soil samples collected from different places of Niniva governorate. The isolates showed bioactivity against test Gram positive and negative bacteria and two Genera of fungi. Streptomyces isolates were identified according to microscopic and morphological tests. The Streptomyces isolates were subjected to ultra violet ray for different time periods. The treated isolates showed little increase in inhibition zone and treated period of (5) minutes showed the best inhibition of the test bacteria. The Streptomyces isolates treated with $\mathrm{N}$ - methyl $-\mathrm{N}-$ nitro $-\mathrm{N}$ - nitroso guaniction at the concentration of (50) $\mu \mathrm{g} / \mathrm{ml}$ showed clear increase of antibiotic production. The isolate Streptomyces III showed clear inhibition against Escherichia coli, Pseudomonas aeruginosa and Bacillus subtilis and the diameter inhibition zone was $(20,29,20) \mathrm{mm}$ respectively.
\end{abstract}




\title{
انتاج مضاد حيوي من مجموعة الماكروليدات من عزلة محلية من البكتريا Streptomyces rimosus
}

\author{
خالا دحام احمد \\ صفاء اسماعيل العبيدي* \\ محمد بشير اسماعيل قاسم \\ قسم علوم الحياة / كلية التربية للعلوم الصرفة \\ جامعة الموصل
}

khalid.ahmed@gmail.com *drsafaaaloaede@yahoo.com Mohammed.ismael@gmail.com DOI: $10.33899 /$ edusj.2019.162959

القبول

الاستلام

2014 / 05 / 08

2014 / 02 / 16

الكلمات المفتاحية: Streptomyces, rimosus, antibiotics, Macrolides

\section{الخلاصة}

تم الحصول على 3 عزلات محلية من جنس Streptomyces 10 عينات تربة جمعت من مناطق مختلفة من محافظة نينوى، بينّت العزلات نشاطاً حيوياً ضد انواع من البكتربا الموجبة والسالبة لصبغة كرام وجنسين من الفطريات. شُخصت عزلات Streptomyces على اساس الاختبارات المايكروسكوبية والثكلية. عُرضت العزلات للأشعة فوق البنفسجية (UV) لفترات مختلفة من الوقت وبيّت العزلات المعاملة زيادة طفيفة

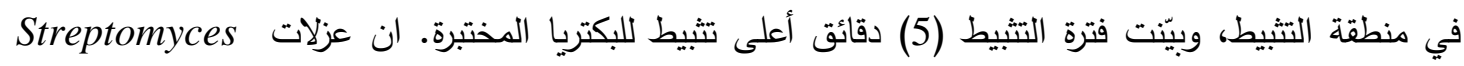

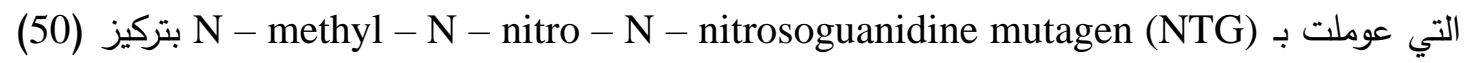
مايكروغرام/مل بيّتت زيادة واضحة بإنتاج المضادات الحيوية. بيّتت العزلة Streptomyces III تثبيط واضح بتركيز ضد Bacillus subtilis و وكان قطر منطقة التثبط

$$
\text { (20،29،20) }
$$

تغير الـ Streptomyces من الكائنات البدائية النواة وحيدة الخلية موجبة لصبغة كرام واسعة الانتشار

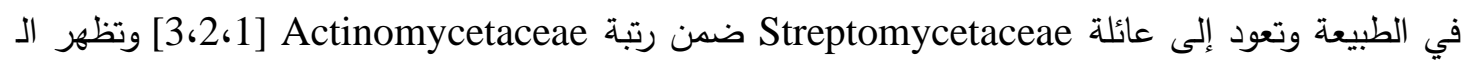
Streptomyces

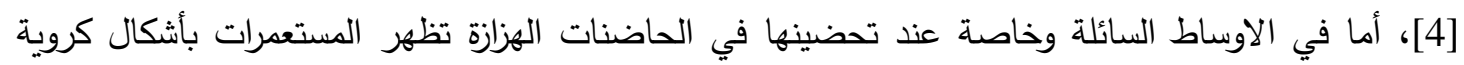
صغيرة وهذا النوع من النمو يكون مرغوباً به في الصناعات التخميرية لسهولة فصلها من الوسط الزرعي الحاوي

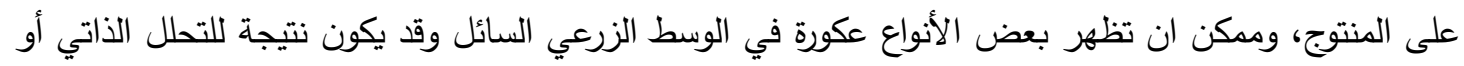

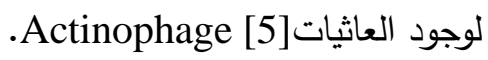


ان الرائحة المميزة التي تتبعث من التربة تكون بسبب وجود الـ Streptomyces التي تتتج المواد

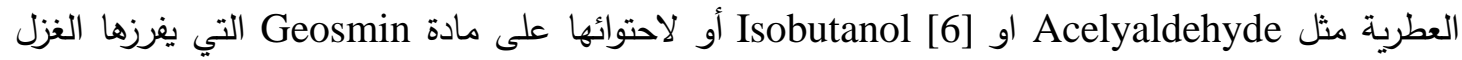

يعد جنس Streptomyces من الكائنات الدقيقة المهمة صناعياً كونه مصدراً جيداً لإنتاج العديد من

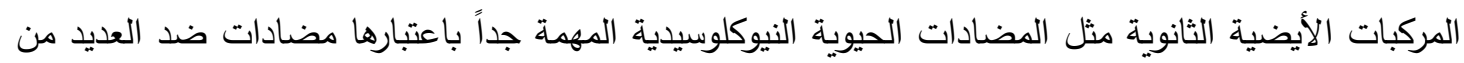
الأمراض السرطانية [8،9]. استخدم عدد كبير من الباحثين Streptomyces rimosus كمصدر جيد لإنتاج العديد من المضادات الحيوية مثل المضاد Oxytetracycline وهو مضاد فعال تجاه الجراثيم الموجبة والسالبة لصبغة كرام .[10] اضافة إلى قابلية هذه العزلة على إنتاج العديد من المضادات النيوكلوسيدية المضادة

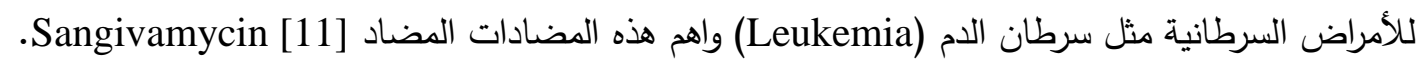
هدف البحث الحالي ينصب في عزل وتشخيص النوع Streptomyces rimosus المنتجة للمواد المثبطة لنمو بعض البكتريا والفطريات الممرضة ذات المقاومة المتعددة للمضادات الحيوية المعزولة من تربة حقول زراعية في محافظة نينوى ومحاولة تشخيص المنتوج تثخيصاً جزئياً.

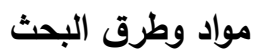

جمع العينات جمعت 5 عينة ترب من مواقع مختلفة من حقول زراعية في محافظة نينوى، ومن عمق (5 الت - 15) سم

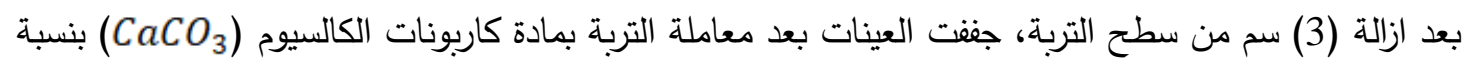

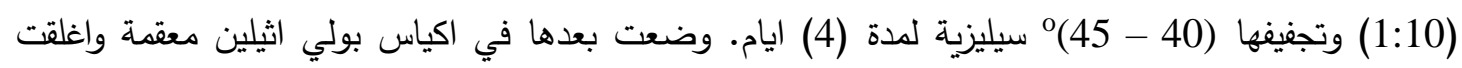
بإحكام ثم وضعت في الثلاجة لحين الاستخدام. اخذ (1) غم من التربة ووضعن في 10 مل مل من انابيب حاوية ماء 10 ماء

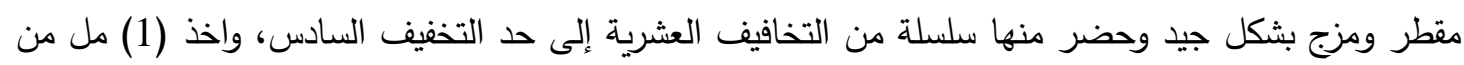
Starch - Casien ) التخفيف الاخير ووضع في طبق بتري معقم وصب عليه الوسط الزرعي نشا - كازائين

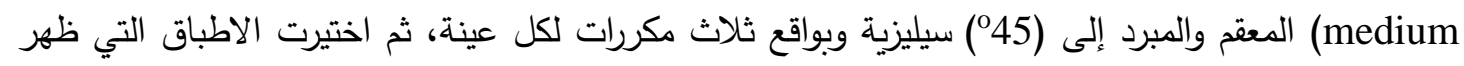

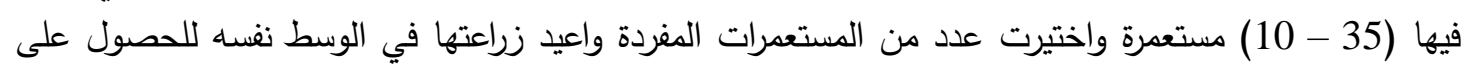

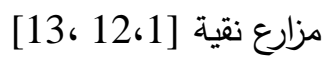

الاوساط الزرعية

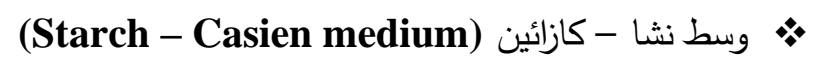

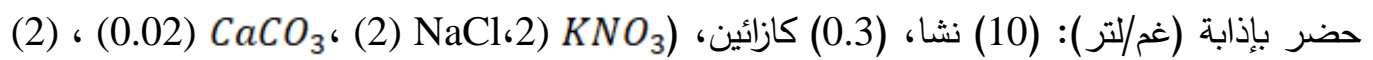

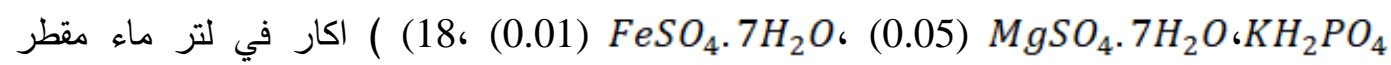
وضبط الاس الهيدروجيني عند (7.2) وعق بالمعقام (14) (Autoclave). استخدم هذا الوسط في العزل.

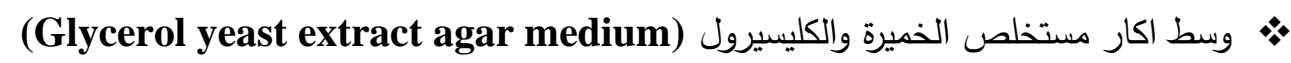

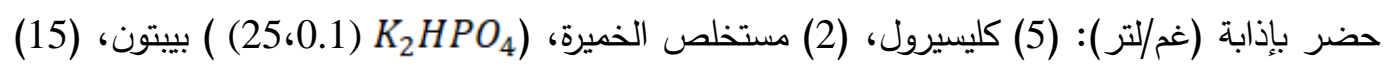

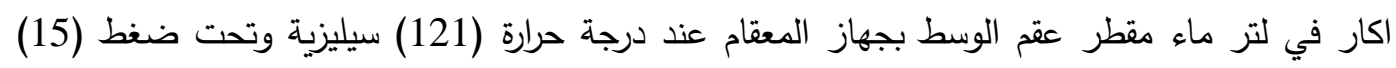

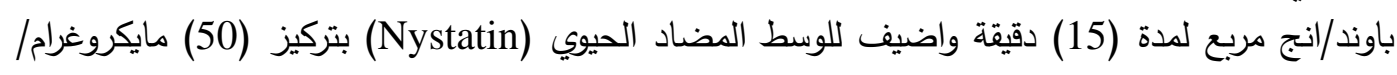

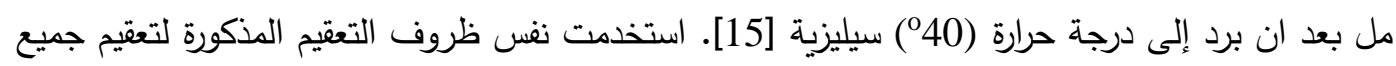
الاوساط المستخدمة في هذا البحث. استخدم هذا الوسط في العزل.

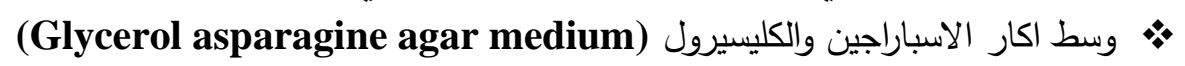

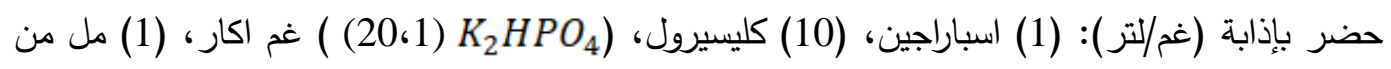

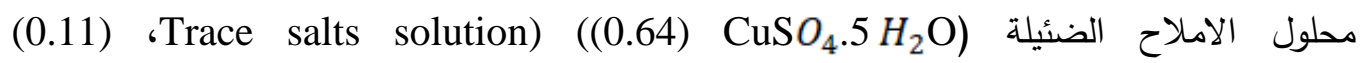


(0.15) $\left.\mathrm{ZnSO}_{4} \cdot 7 \mathrm{H}_{2} \mathrm{O}\right)$ ، (0.79) $\mathrm{MnCl}_{2} \cdot 4 \mathrm{H}_{2} \mathrm{O}$ ، $\mathrm{FeSO}_{4} \cdot 7 \mathrm{H}_{2} \mathrm{O}$ الهيدروجيني عند (7.4) وعقم بالمعقام [16]. استخدم هذا الوسط في العزل. استخدم هذا الوسط في العزل.

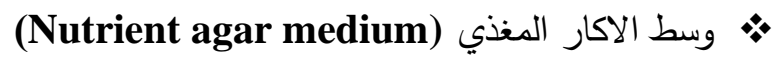

حضر هذا الوسط حسب تعليمات الشركة المجهزة (Oxiod) بإذابة (23) غم من الاكار المغذي في (1) لتر ماء مقطر وضُبط الاس الهيدروجيني عند (7.2) وعقم بالمعقام. استخدم هذا الوسط للفعالية الضدية.

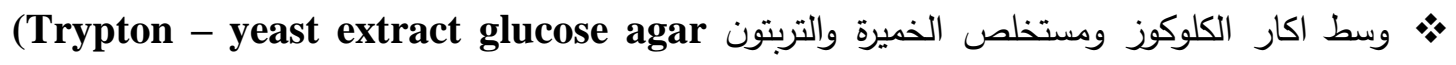
medium)

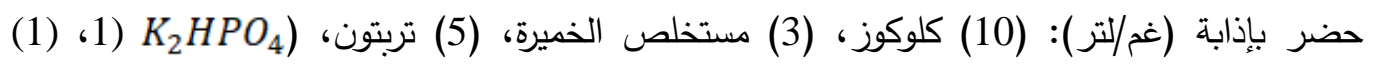
ه (20،KH ${ }_{2} P_{4}$

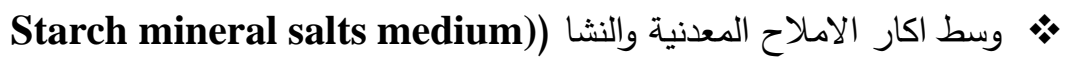

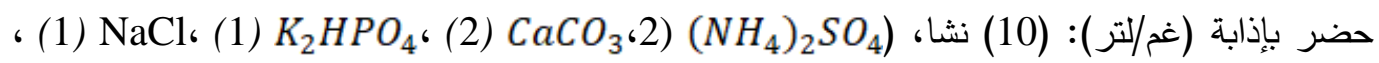

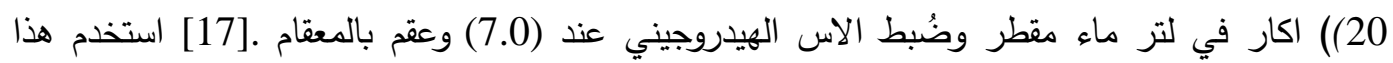
الوسط في العزل.

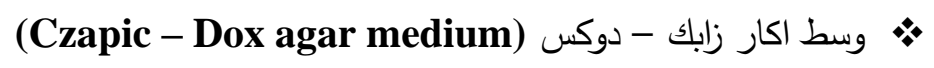

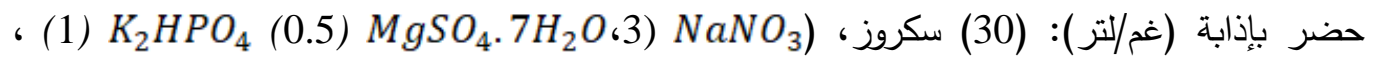
ليعقام بالمعقام .18] استخدم هذا الوسط في العزل. استخدم هذا الوسط في العزل.

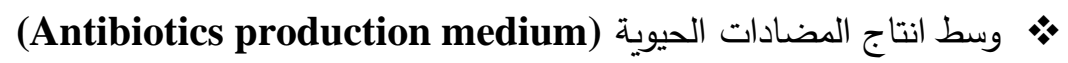

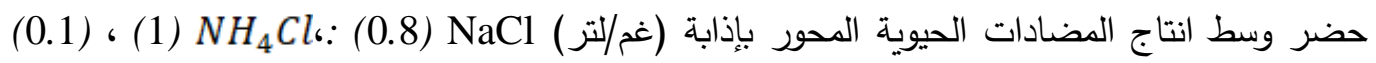
(0.04) CaCl ، (0.1) $\mathrm{MgSO}_{4}$. $7 \mathrm{H}_{2} \mathrm{O}$ ، $\mathrm{K}_{2} \mathrm{HPO}_{4}$ لتر ماء مقطر وضُبط الاس الهيدروجيني عند (7.3) وعقم بالمعقام [11].

Streptomyces تشخيص عزلة

شخصت العزلات التي شك انها تابعة لجنس Streptomyces اعتماداً على لون وشكل المستعمرات على وسط اكار الاملاح المعدنية والنشا وشكل الغزل الهوائي والارضي وترتيب سلاسل السبورات باستخدام تقنية الزرع على الثريحة الزجاجية (16) (2،Slid culture technique) .

بكتربا الاختبار

، Staphylococcus aurous، Bacillus subtilis،Escherichia coli استخدمت البكتريا

Candida ، Enterobacter aerogene، Proteus vulgaris،Pseudomonas aeruginosa albicans الموصل لغرض تحديد الفعالية التضادية لعزلات Streptomyces المعزولة.

Streptomyces اختبار الفعالية التضادية لعزلات لغرض اختبار قابلية عزلة Streptomyces لإنتاج المضادات الحيوية تم استخدام طريقة الانتشار

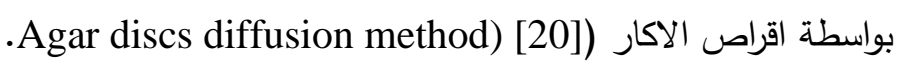


تشخيص عزلة Streptomyces المنتخبة

تم تشخيص العزلة المنتخبة والتي أعطت أعلى تضاد ضد الفطر Asperigillus niger إلى مستوى

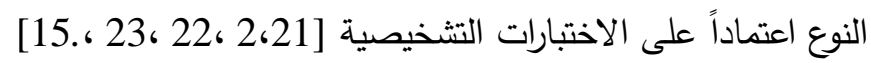

تحضير اللقاح

حضر وسط اللقاح من مكونات وسط الإنتاج نفسها. ووزع في دوارق زجاجية مخروطية سعة (250)

مل بواقع (50) مل لكل دورق عُم ثم لُقح بنقل جزء (حملة لوب) من مزرعة بكتريا Streptomyces النامية

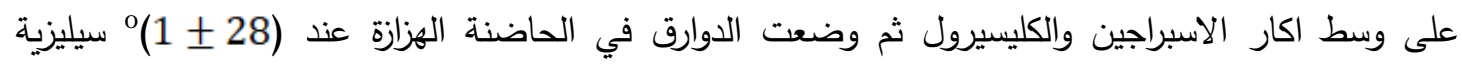
وبسرعة رج (140) دورة/ دقيقة لمدة (3) ايام.

حضر وسط انتاج المضادات الحيوية في دوارق زجاجية مخروطية سعة (250) مل بواقع (50) مل

الظروف الزرعية

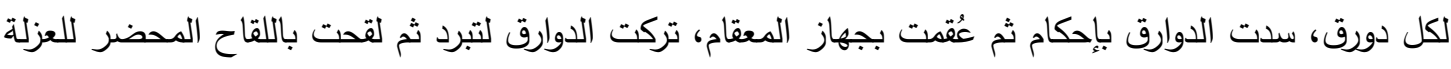

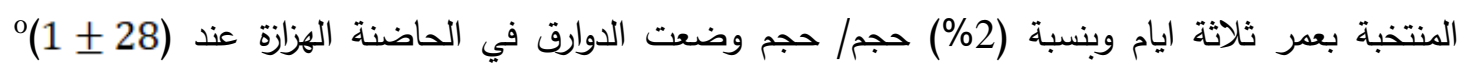
سيليزية وبسرعة رج (140) دورة/ دقيقة لمدة (7) ايام.

استخلاص المضاد الحيوي للعزلة المنتخبة ودراسة فعاليته البايولوجية تمت عملية استخلاص المضاد الحيوي بطريقة محلول ايثايل استيت وحسب طرئه وريقة [24] و Ilic وآخرون [19] ولغرض دراسة الفعالية البايولوجية للمادة المستخلصة تم استخدام طريقة الانتشار بالأقراص حيث حضرت اقراص من ورق الترشيح (Whatmann No. 1) بقطر (6) سم وغمرت بالبة بالمادة المستخلصة المذابة في الماء ثم جفقت في الهواء ووضعت في الطبات الهراق حاوية على وسط الاكار المغذي والملقح بيكتريا (S. aureus) حُضنت الاطباق عند (37 1 1) سيليزية لمدة (24) ساعة وتم قياس المنطقة الخالية من النمو للبكتريا والفطريات المختبرة.

تنقية المضاد الحيوي بعد استخلاص المادة الفعالة اجريت عملية فصل المركبات التي تحتويها المادة المستخلصة باستخدام

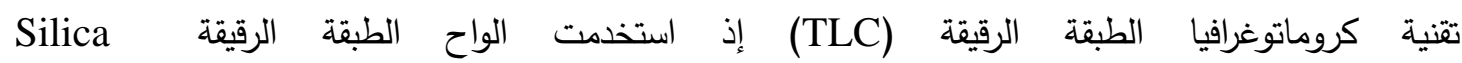
ماء 20 سم. واستخدم محلول التشرب المتكون من بيوتانول: حامض الخليك: 20 × 254 Merk plate ماء بنسب $4: 1$ : 2 ثم اظهرت بقع المركبات المفصولة اما باستخدام التبخير بواسطة اليود أو تعريض اللوح

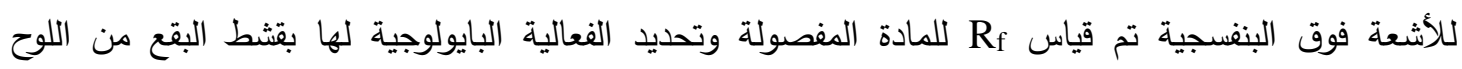

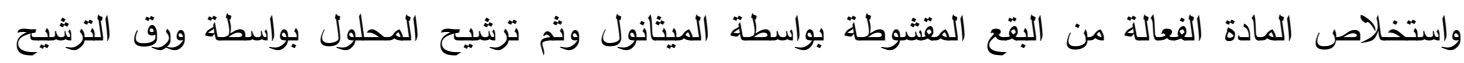

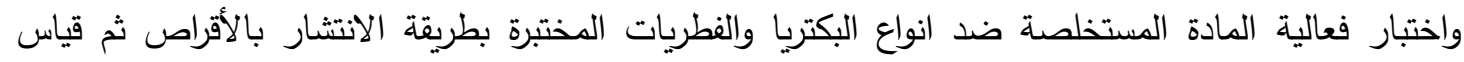

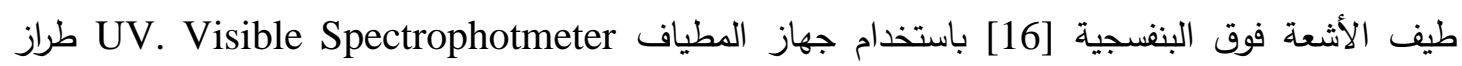
.Camspec M330 UK

\section{النتائج والمناقشة}

العزل

تم عزل 15 عزلة تابعة إلى جنس Streptomyces من (5) عينات ترب جمعت من مواقع مختلفة من حقول زراعية لمحافظة نينوى. اختيرت العزلة اعتماداً على المظهر الطباشيري للمستعمرة النامية على اوساط 
العزل وانتاجها رائحة الأرض الرطبة [26،25] ـ وكانت لمعاملة التربة بمادة كاربونات الكالسيوم

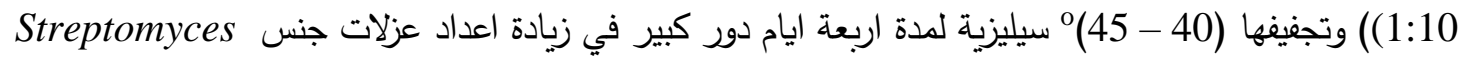

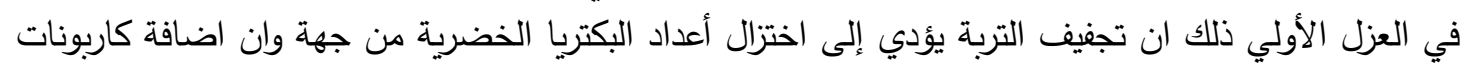

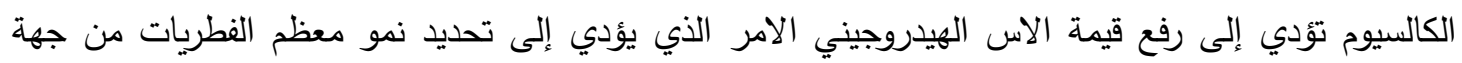
اخرى وبذلك تنمو البكتريا الخيطية.[27]

شخصت العزلات التابعة إلى جنس Streptomyces باستخدام تقنية الزرع على الشريحة الزجاجية إذ

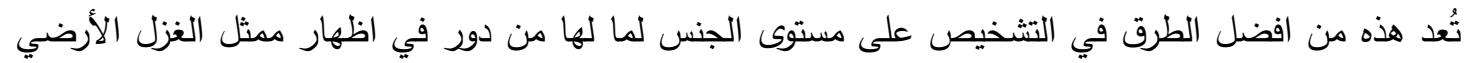

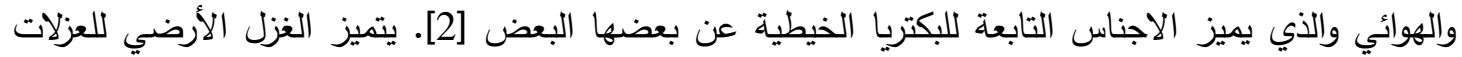

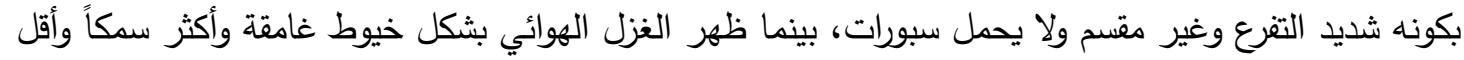

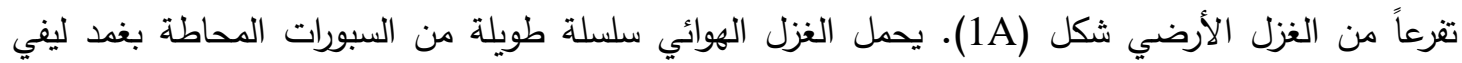

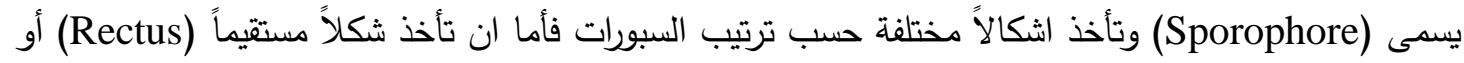
حلزونياً (Spiral) أو مستقيماً ذات نهاية معقوفة (Retinaculum - Apertum) أو مستقيماً متموجاً (Sectus)

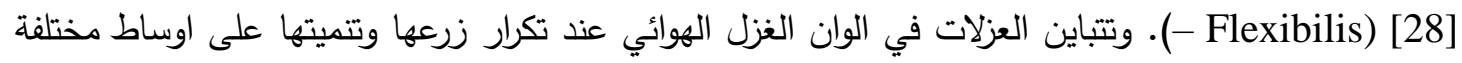

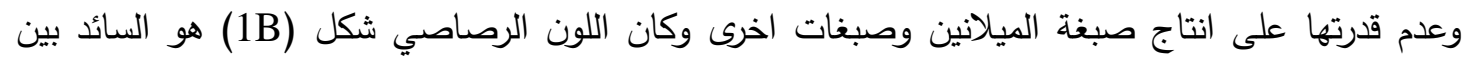

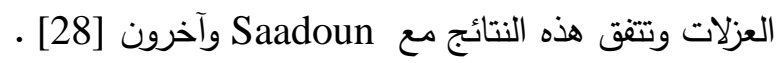

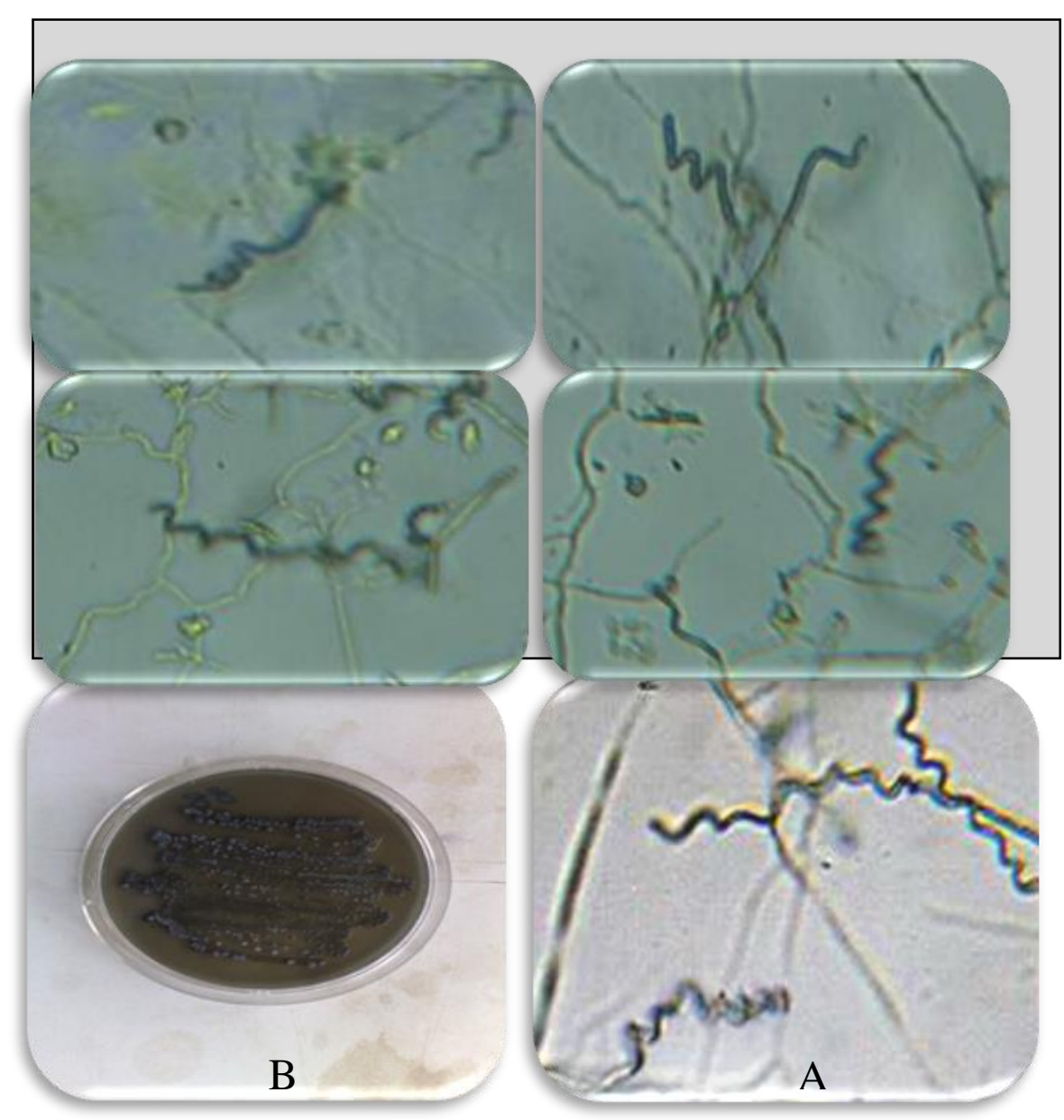

شكل (A): (1) الثكل الحزوني للسلاسل السبورات لعزلة Streptomyces rimosus بقوة تكبير 40X.

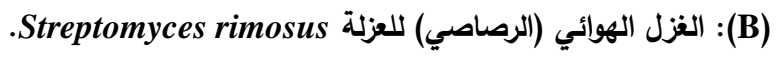




\section{انتاج المضادات الحيوية}

تم انتخاب العزلة التي اعطت أعلى تأثير ضد البكتريا والفطريات المختبرة شكل (2) وتم تشخيصها إلى

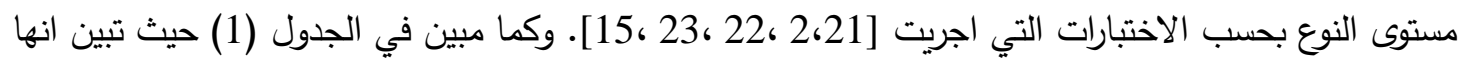

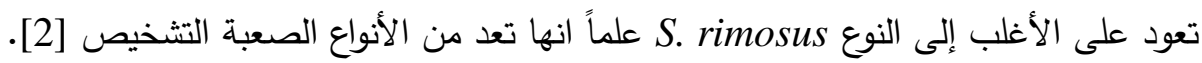

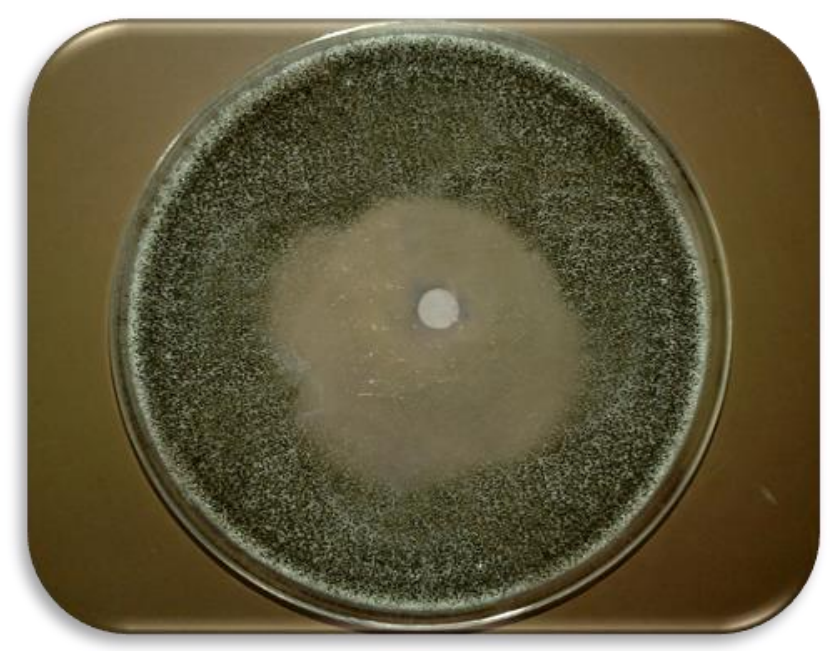

شكل (2): تأثير المضاد الحيوي للعزلة المحلية على الفطر A. niger.

جدول (1): الاختبارات التشخيصية للعزلة المنتخبة.

\begin{tabular}{|c|c|}
\hline 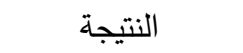 & الاختبارات \\
\hline+ & صبغة كرام \\
\hline- & الصبغة المقاومة للحامض \\
\hline 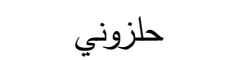 & شكل سلسلة السبور \\
\hline رصاصي - ابيض & ل ل لون الغزل الهوائي \\
\hline- & تكوين السبورات على الغزل الأرضي \\
\hline- & انتاج الميلانين على وسط Tyrosine agar \\
\hline \multicolumn{2}{|c|}{ الاختبارات الأنزيمية } \\
\hline+ & 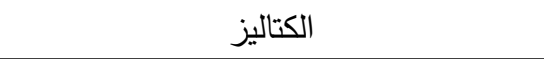 \\
\hline+ & الاوكسيديز \\
\hline- & 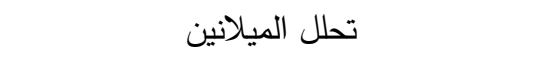 \\
\hline+ & تحلل السثين \\
\hline- & اختزال اللترات الت \\
\hline- & انتاج \\
\hline+ & تحلل النشا \\
\hline- & تحلل الكازائين \\
\hline+ & انتاج انزيم DNase \\
\hline+ & تحلل اليوريا \\
\hline
\end{tabular}


انتاج مضاد حيوي من مجموعة الماكروليدات من عزلة محلية من البكتريا Streptomyces rimosus.

\begin{tabular}{|c|c|}
\hline \multicolumn{2}{|c|}{ استهلاك المصادر الكاربونية } \\
\hline- & كلوكوز \\
\hline+ & فركتوز \\
\hline+ & سكروز \\
\hline+ & مانيتول \\
\hline+ & اثيوسيتول \\
\hline+ & مالتوز \\
\hline+ & كالكتوز \\
\hline+ & لاكتوز \\
\hline+ & زايلوز \\
\hline++ & نشا \\
\hline- & دكستران \\
\hline++ & كليسرول \\
\hline \multicolumn{2}{|c|}{ القدرة على النمو باستخدام تراكيز مختلفة من المواد الكيميائية } \\
\hline+ & $(1.5 \%) \mathrm{NaCl}$ \\
\hline+ & $(3 \%) \mathrm{NaCl}$ \\
\hline+ & $(5 \%) \mathrm{NaCl}$ \\
\hline- & $(7 \%) \mathrm{NaCl}$ \\
\hline- & $(10 \%) \mathrm{NaCl}$ \\
\hline+ & صوديوم ازايد (0.01\%) \\
\hline- & مثينول(0.1\%) \\
\hline- & القدرة على النمو في (45 o سيليزية \\
\hline \multicolumn{2}{|c|}{ القدرة على تثبط ندو البكتريا الموجبة والسالبة } \\
\hline & B. subtilis \\
\hline & S. aurous \\
\hline & E. coli \\
\hline & P. aeruginosa \\
\hline & E. aerogene \\
\hline & P. vulgaris \\
\hline
\end{tabular}

\begin{tabular}{|c|c|}
\hline \multicolumn{2}{|c|}{ القدرة على تثبط نمو الخميرة والفطريات } \\
\hline C. albicans & C. albicans \\
\hline A. niger & A. niger \\
\hline $\begin{array}{c}\text { شكل النمو في الوسط السائل } \text { Gasien starch } \\
\text { شasi }\end{array}$ & $\begin{array}{c}\text { شكل النمو في الوسط السائل } \text { Gasien starch } \\
\text { شائl }\end{array}$ \\
\hline \multicolumn{2}{|c|}{ حساسية الـ Streptomyces للمضادات الحيوية } \\
\hline $\mathbf{R}$ & Chloramphenicol \\
\hline
\end{tabular}




\begin{tabular}{|c|c|}
\hline & (30) مايكروغرام/مل \\
\hline $\mathbf{R}$ & $\begin{array}{c}\text { Neomycin } \\
\text { (30) مايكروغراج/مل }\end{array}$ \\
\hline $\mathbf{R}$ & $\begin{array}{c}\text { Rifampin } \\
\text { (30) مايكروغرام/مل }\end{array}$ \\
\hline $\mathbf{R}$ & $\begin{array}{c}\text { Streptomycin } \\
\text { (30) مايكروغرام/مل }\end{array}$ \\
\hline $\mathbf{S}$ & $\begin{array}{c}\text { Ampicillin } \\
\text { (30) مايكروغرام/مل }\end{array}$ \\
\hline $\mathbf{S}$ & $\begin{array}{c}\text { Gentamycin } \\
\text { (30) مايكروغرام/مل }\end{array}$ \\
\hline
\end{tabular}

تشخيص المضاد الحيوي

تم تثخيص المضاد الحيوي من قبل العزلة المنتخبة S. rimosus باستخدام كروماتوغرافيا الطبقة

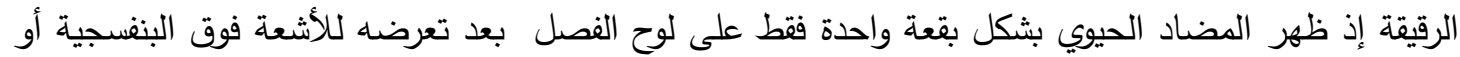

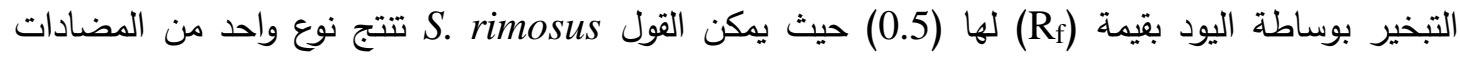

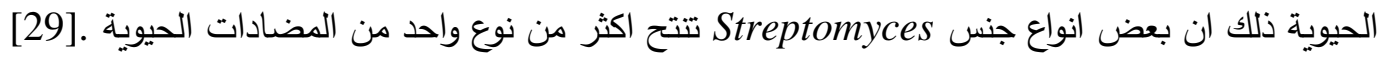
تم عزل المضاد الحيوي من البقعة الظاهرة على لوح الفصل حيث تبين انه قهوائي اللون. تم قياس طيف الأشعة فوق البنفجية للمضاد المذاب في الماء حيث اظهرت ذربه ذروة امتصاص عند

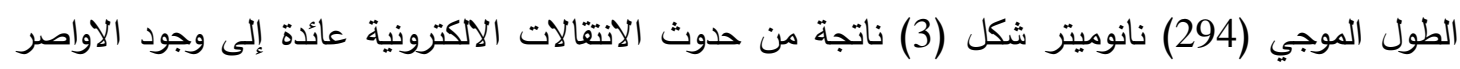
المزدوجة في تركيبة المضاد من نوع (C= O) و [30] (C) (3).) واعتماداً على [31] فان المضاد الحيوي المنتج من قبل S. rimosus يعود على الأغلب إلى مجموعة مضادات المايكروليد.

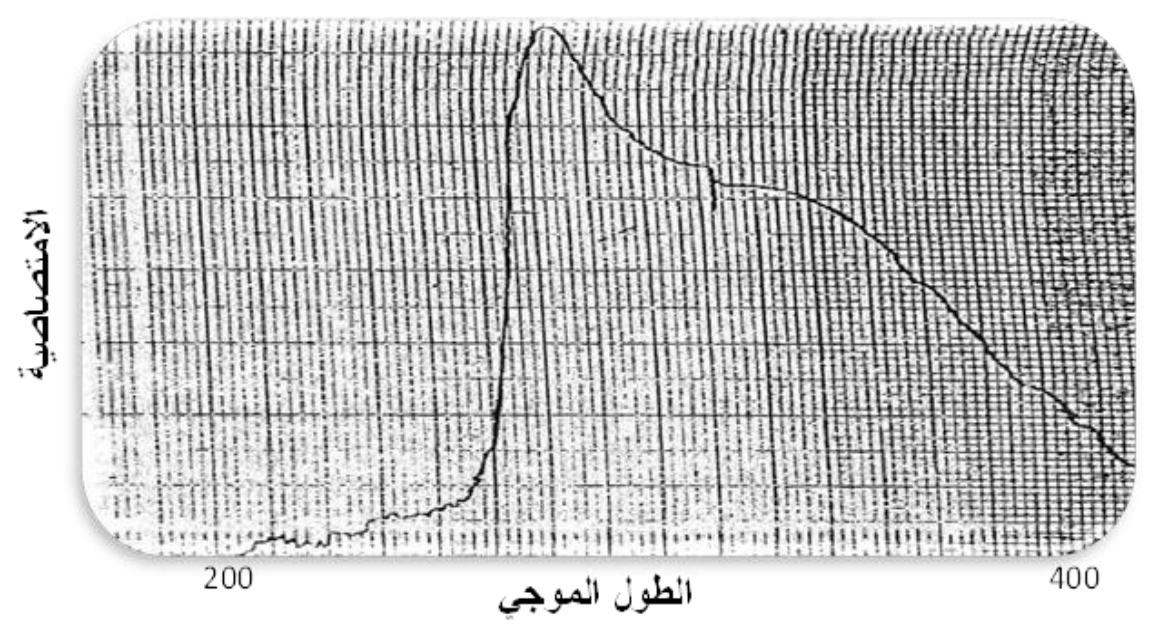

شكل (3): طيف الأثعة فوق البنفجية للمضاد الحيوي المستخلص من العزلة المحلية Streptomyces rimosus. 
من ملاحظة طيف الأشعة تحت الحمراء شكل (4) الذي يعتبر أهم الحزم الموجودة في المضاد الحيوي

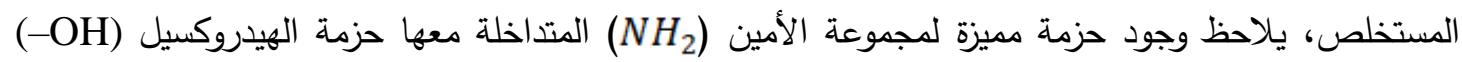

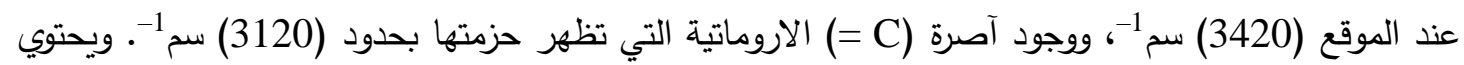
المركب ايضاً على الآصرة (C=O) الكاربونيلية العائدة إلى مجموعة الامايد، وتظهر حزمتها عند الموقع

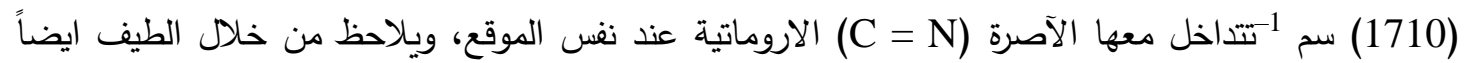

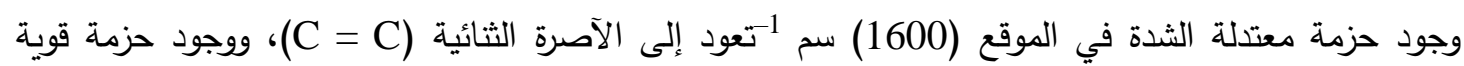
الثدة في الموقع (1400) سم 1-تدل على آصرة (C - N) ضمن تركيبة المضاد الحيوي. ان ظهور تلك الحزم في طيف الأشعة تحت الحمراء للمضاد الحيوي الجديد يتوافق مع أهم حزم الامتصاص الظاهرة في طيف الأثعة S. rimosus تحت الحمراء للمضاد الحيوي المعزول من فيعه

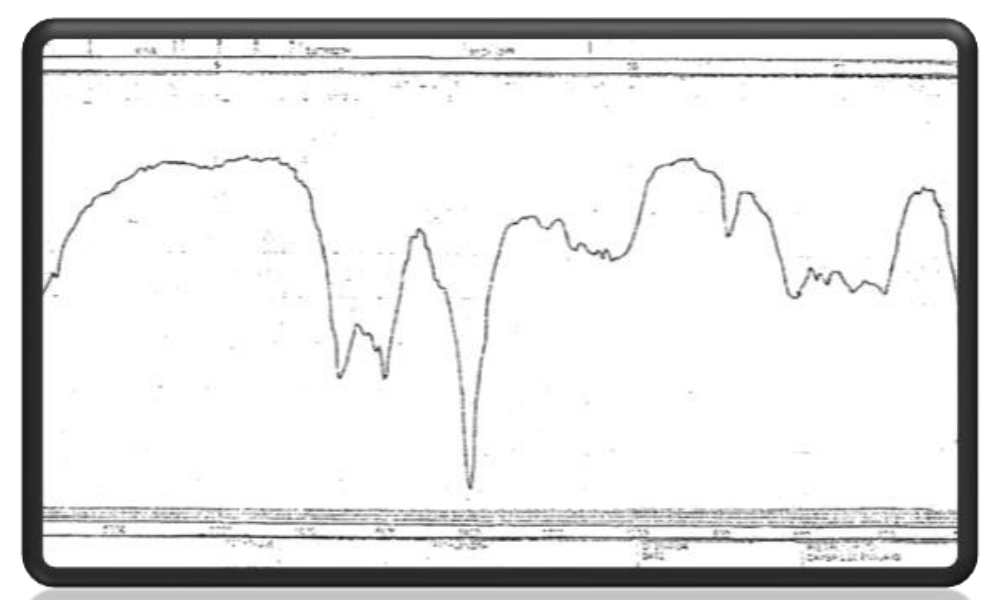

شكل (4): يوضح طيف الأشعة تحت الحمراء للمضاد الحيوي المستخلص للعزبة Streptomyces rimosus

\section{References}

1) Vercesi, A.; Nasini, G. and Locci, R. (1992). Actinomyces Vol. 3, No. 1.

2) Holt, J. G.; Kreig, N. R.; Sneath, P. H. A.; Staley, J. T. and Williams, S. T. Bergey's (1994). Williams and Wilkins, Baltimore, U. S. A.

3) Ifaat, H. M. (2003). Journal of Mediterranean Ecology Vol. 4, No. 3 - 4.

4) Gilberto, H. (1983). Ph. D. Thesis. Swiesfedral institnte of technology Zaerich.

5) Todar, K. (2008). University of Wisconsin Madison Department of bacteriology.

6) Cross, T. and Good fellow. M. (1984). In (Sykes, G. and Skinner, F. A. eds.) pp. 11 - 112. Actinomycetales, Characteristics and Practical importance. Academic press, London. New York.

7) Locci, R. (1989). In (Williams, T. T.; Showp, M. E. and Holt, J. G. eds). 4: 2451 -2508 . Bergeys of manual of systemic bacteriology. Williams and Wilkins Co., Baltimore.

8) Rao, K. V.; Marsh, W. S. and Renn, D. W. (1969). U. S. Part. 862, 423, 398.

9) Haque, S. F.; Sen, S. K. and Pal, S. C. (1993). Indian Biologist. 25(1): $51-55$.

10) Egorov, N. S. (1985). Antibiotics. A Scientific Approach. Mir Publishers, Moscow, Russia.

11) Rao, K. V. and Renn, D. W. (1963). Antimicrobial agents. Chemotherapy. 77. Rao, K. V. (1968). J. Med. Chem. 11. 939. 
12) Al-Obaidi, S. I. (2012). Isolation of Different Local Species of the Genus Streptomyces and Study of their Antimicrobial Activity Identification by Biochemical Tests and Obtaining of Genetic Variation of Isolates by PCR RAPD Technique. Ph.D. Thesis, College of Education, University of Mosul. Mosul, Iraq.

13) Geylan, O.; Okmen, G. and Uzgur, A. (2008). Eurasia J. Bio. Sci. 2: 73 - 82.

14) Kuster, E. and Williams, S. T. Nature. 202: 928 - 929.

15) Oskay, M.; Tamer, U. and Azeri, C. (2004). Afr. J. Biotechnol. 3: 221 - 446.

16) Williams, S. T. and Cross, T. (1971). In Method in Microbiology. Vol. 4 Booth, C. pp295.

17) Wu, R. Y. and Chen, M. H. (1995). Bot. Bull. Acad Sin., 36: 201 - 205.

18) Lennette, E. H.; Balows, A.; Hausler, W. J. and Shadomy, H. J. (1985). Washington, USA.

19) Ilic, S. B.; Konstantinovic, S. S. and Todorovic, Z. B. (2005). Series: Medicine and Biology, 12: $44-46$.

20) Egorov, N. S. (1992). MIR Publishers, Moscow; $62-75$ and $132-176$.

21) Williams, S. T.; Goodfellow, M.; Wellington, E. M. H.; Vickers, J. C.; Alderson, G.; Sneath, P. H. A.; Sackin, M. J. and Mortimer, A. M. (1983). J. Gen. Microbiol. 129: 1815 - 1830.

22) Pridham, T. G. and Gottleib, D. (1984). J. Bacteriol., 56: 107 - 114.

23) Lechevalier, H. A. and Lechevalier, M. P. (1981). Starr, M. P.; Stolp, H.; Truper, H. G.; Balows, A. and Schlegel, H. G. (eds). Vol. 1, Springer - Verlag.

24) Sahin, N. and Ugur, A. (2003). Turk. J. Biol. 27: 79 - 84.

25) Carpenter, P. L. (1977). W. B. Saunders Comp.; U. S. A.

26) Alexander, M. (1977). John wiley and Sons.

27) Nahar, H., S.; Marof, B. Al-Deen and Al-Mahana, A. N. (1997). Babel university, 3:201-208.

28) Saadoun, I.; Al - Momani, F.; Malkawi, H. and Mohammad, M. J. (1999). Microbios., 100: $41-46$.

29) Waksman, S. A. (1967). The Actinomyces. A summary of current knowledge.

30) Lambert, J. B.; Herbert, F. S.; Davied, L.; Grahamcooks, R. (1987). Macmillan Publishing Company / New York. Macmillan Publishers / London.

31) Berdy, J. (1980). Hand Book of Antiibiotic compound Vol. 11. Macrocyclic Lacton (Lactam) Antibiotics. 